\title{
Coronavirus and Gordon Life Science Institute
}

\section{Kuo-Chen Chou}

Gordon Life Science Institute, Boston, Massachusetts 02478, United States of America

Correspondence to: Kuo-Chen Chou, kcchou@gordonlifescience.org, kcchou38@gmail.com

Keywords: Pandemic COVID-19, The End of World, The Holy Bible Prophecy, The Deducted Outcomes of Many Philosophers

Received: July 1, 2020 Accepted: July 7, $2020 \quad$ Published: July 10, 2020

Copyright () 2020 by author(s) and Scientific Research Publishing Inc.

This work is licensed under the Creative Commons Attribution International License (CC BY 4.0).

http://creativecommons.org/licenses/by/4.0/

(c) (i) Open Access

\section{ABSTRACT}

The impacts of coronavirus to our planet are unprecedented; i.e., they are going to eliminate the entire mankind. Driven by such horrible situation, some philosophical viewpoints have naturally happened. Whether the "World End" must come? If yes, when? During this waiting period, the best way to do science is via the Internet Institute, such as "Gordon Life Science Institute", and the results thus achieved will be most rewarding.

\section{INTRODUCTION}

As of June-30-2020, more than 200 countries on our planet have been attacked by the coronavirus disease 2019 (COVID-19): for USA alone with reported 2,682,424 cases of which 128,824 resulted in deaths; for United Kingdom with 312,654 cases and 43,730 deaths.

\section{FACTS AND DISCUSSIONS}

The damage power of COVID-19 is overwhelmingly stronger than "atomic bombs" (2nd World War, 1945) or any kind of terrorists ("911", 2001). The death number has also far exceeded the death number reported for any war of USA history. Accordingly, such unprecedented power must come from the "Creator" rather than from being created human beings.

Coronavirus disease 2019 (COVID-19) is an infectious disease caused by severe acute respiratory syndrome, which was first identified in December 2019 in Wuhan, Hubei, China. After April 2020 and causing about 4,000 deaths, although no remarkable infectious cases reported in Wuhan. Unfortunately, the $2^{\text {nd }}$-round coronavirus diseases have started landing on Beijing during May 2020. This kind of first from "Eastern countries" to Western Countries" and then as a feedback from the West to the East, very much like playing "ping-pong" or "Tennis" ball. Here, the ball is none but the "Coronavirus".

Facing such environments, all the scientists working in a sharing laboratory of the Universities or most conversional Institutes must or being forced to wear masks except those working in the "Internet Institute" such as the "Gordon Life Scient Institute" $[1,2]$. And the results thus obtained will be most awarding as elaborated in [3]. As concurred by a series of interesting publications, particularly for the idea 
of "Pseudo Amino Acid Composition" [4-99], and “5-Steps Rule” [100-140].

\section{CONCLUSIONS}

For the planet where we are staying, after several rounds of the killings as described in the Section 2, its "End" will be expedited exponentially with time. Before its "End", it will be most awarding to do science with the "Internet Institutes".

\section{CONFLICTS OF INTEREST}

The authors declare no conflicts of interest regarding the publication of this paper.

\section{REFERENCES}

1. Chou, K.C. (2019) The Cradle of Gordon Life Science Institute and Its Development and Driving Force. International Journal of Biological Genetics, 1, 1-28.

2. Chou, K.C. (2019) Intriguing Story about the Birth of Gordon Life Science Institute and Its Development and Driving Force. Journal of Retro Virology and Anti Retro Virology, 1, Article ID: 180002.

3. Chou, K.C. (2020) The Development of Gordon Life Science Institute: Its Driving Force and Accomplishments. Natural Science, 12, 202-217. https://doi.org/10.4236/ns.2020.124018

4. Ding, Y.S. and Zhang, T.L. (2008) Using Chou's Pseudo Amino Acid Composition to Predict Subcellular Localization of Apoptosis Proteins: An Approach with Immune Genetic Algorithm-Based Ensemble Classifier. Pattern Recognition Letters, 29, 1887-1892. https://doi.org/10.1016/j.patrec.2008.06.007

5. Fang, Y., Guo, Y., Feng, Y. and Li, M. (2008) Predicting DNA-Binding Proteins: Approached from Chou's Pseudo Amino Acid Composition and Other Specific Sequence Features. Amino Acids, 34, 103-109.

https://doi.org/10.1007/s00726-007-0568-2

6. Jiang, X., Wei, R., Zhang, T.L. and Gu, Q. (2008) Using the Concept of Chou's Pseudo Amino Acid Composition to Predict Apoptosis Proteins Subcellular Location: An Approach by Approximate Entropy. Protein \& Peptide Letters, 15, 392-396. https://doi.org/10.2174/092986608784246443

7. Jiang, X., Wei, R., Zhao, Y. and Zhang, T. (2008) Using Chou's Pseudo Amino Acid Composition Based on Approximate Entropy and an Ensemble of AdaBoost Classifiers to Predict Protein Subnuclear Location. Amino Acids, 34, 669-675. https://doi.org/10.1007/s00726-008-0034-9

8. Li, F.M. and Li, Q.Z. (2008) Predicting Protein Subcellular Location Using Chou's Pseudo Amino Acid Composition and Improved Hybrid Approach. Protein \& Peptide Letters, 15, 612-616.

https://doi.org/10.2174/092986608784966930

9. Lin, H. (2008) The Modified Mahalanobis Discriminant for Predicting Outer Membrane Proteins by Using Chou's Pseudo Amino Acid Composition. Journal of Theoretical Biology, 252, 350-356.

https://doi.org/10.1016/j.jtbi.2008.02.004

10. Lin, H., Ding, H., Guo, F.B., Zhang, A.Y. and Huang, J. (2008) Predicting Subcellular Localization of Mycobacterial Proteins by Using Chou's Pseudo Amino Acid Composition. Protein \& Peptide Letters, 15, 739-744. https://doi.org/10.2174/092986608785133681

11. Nanni, L. and Lumini, A. (2008) Genetic Programming for Creating Chou's Pseudo Amino Acid Based Features for Submitochondria Localization. Amino Acids, 34, 653-660. https://doi.org/10.1007/s00726-007-0018-1

12. Zhang, G.Y., Li, H.C., Gao, J.Q. and Fang, B.S. (2008) Predicting Lipase Types by Improved Chou's Pseudo Amino Acid Composition. Protein \& Peptide Letters, 15, 1132-1137.

https://doi.org/10.2174/092986608786071184 
13. Zhang, S.W., Chen, W., Yang, F. and Pan, Q. (2008) Using Chou's Pseudo Amino Acid Composition to Predict Protein Quaternary Structure: A Sequence-Segmented PseAAC Approach. Amino Acids, 35, 591-598. https://doi.org/10.1007/s00726-008-0086-x

14. Zhang, S.W., Zhang, Y.L., Yang, H.F., Zhao, C.H. and Pan, Q. (2008) Using the Concept of Chou's Pseudo Amino Acid Composition to Predict Protein Subcellular Localization: An Approach by Incorporating Evolutionary Information and von Neumann Entropies. Amino Acids, 34, 565-572. https://doi.org/10.1007/s00726-007-0010-9

15. Chen, C., Chen, L., Zou, X. and Cai, P. (2009) Prediction of Protein Secondary Structure Content by Using the Concept of Chou's Pseudo Amino Acid Composition and Support Vector Machine. Protein \& Peptide Letters, 16, 27-31. https://doi.org/10.2174/092986609787049420

16. Georgiou, D.N., Karakasidis, T.E., Nieto, J.J. and Torres, A. (2009) Use of Fuzzy Clustering Technique and Matrices to Classify Amino Acids and Its Impact to Chou's Pseudo Amino Acid Composition. Journal of Theoretical Biology, 257, 17-26. https://doi.org/10.1016/j.jtbi.2008.11.003

17. Li, Z.C., Zhou, X.B., Dai, Z. and Zou, X.Y. (2009) Prediction of Protein Structural Classes by Chou's Pseudo Amino Acid Composition: Approached Using Continuous Wavelet Transform and Principal Component Analysis. Amino Acids, 37, 415-425. https://doi.org/10.1007/s00726-008-0170-2

18. Lin, H., Wang, H., Ding, H., Chen, Y.L. and Li, Q.Z. (2009) Prediction of Subcellular Localization of Apoptosis Protein Using Chou's Pseudo Amino Acid Composition. Acta Biotheoretica, 57, 321-330. https://doi.org/10.1007/s10441-008-9067-4

19. Qiu, J.D., Huang, J.H., Liang, R.P. and Lu, X.Q. (2009) Prediction of G-Protein-Coupled Receptor Classes Based on the Concept of Chou's Pseudo Amino Acid Composition: An Approach from Discrete Wavelet Transform. Analytical Biochemistry, 390, 68-73. https://doi.org/10.1016/j.ab.2009.04.009

20. Zeng, Y.H., Guo, Y.Z., Xiao, R.Q., Yang, L., Yu, L.Z. and Li, M.L. (2009) Using the Augmented Chou's Pseudo Amino Acid Composition for Predicting Protein Submitochondria Locations Based on Auto Covariance Approach. Journal of Theoretical Biology, 259, 366-372. https://doi.org/10.1016/j.jtbi.2009.03.028

21. Esmaeili, M., Mohabatkar, H. and Mohsenzadeh, S. (2010) Using the Concept of Chou's Pseudo Amino Acid Composition for Risk Type Prediction of Human Papillomaviruses. Journal of Theoretical Biology, 263, 203-209. https://doi.org/10.1016/j.jtbi.2009.11.016

22. Gu, Q., Ding, Y.S. and Zhang, T.L. (2010) Prediction of G-Protein-Coupled Receptor Classes in Low Homology Using Chou's Pseudo Amino Acid Composition with Approximate Entropy and Hydrophobicity Patterns. Protein \& Peptide Letters, 17, 559-567. https://doi.org/10.2174/092986610791112693

23. Mohabatkar, H. (2010) Prediction of Cyclin Proteins Using Chou's Pseudo Amino Acid Composition. Protein \& Peptide Letters, 17, 1207-1214. https://doi.org/10.2174/092986610792231564

24. Qiu, J.D., Huang, J.H., Shi, S.P. and Liang, R.P. (2010) Using the Concept of Chou's Pseudo Amino Acid Composition to Predict Enzyme Family Classes: An Approach with Support Vector Machine Based on Discrete Wavelet Transform. Protein \& Peptide Letters, 17, 715-722. https://doi.org/10.2174/092986610791190372

25. Sahu, S.S. and Panda, G. (2010) A Novel Feature Representation Method Based on Chou's Pseudo Amino Acid Composition for Protein Structural Class Prediction. Computational Biology and Chemistry, 34, 320-327. https://doi.org/10.1016/j.compbiolchem.2010.09.002

26. Yu, L., Guo, Y., Li, Y., Li, G., Li, M., Luo, J., Xiong, W. and Qin, W. (2010) SecretP: Identifying Bacterial Secreted Proteins by Fusing New Features into Chou's Pseudo Amino Acid Composition. Journal of Theoretical Biology, 267, 1-6. https://doi.org/10.1016/j.jtbi.2010.08.001

27. Guo, J., Rao, N., Liu, G., Yang, Y. and Wang, G. (2011) Predicting Protein Folding Rates Using the Concept of 
Chou's Pseudo Amino Acid Composition. Journal of Computational Chemistry, 32, 1612-1617. https://doi.org/10.1002/jcc. 21740

28. Lin, J. and Wang, Y. (2011) Using a Novel AdaBoost Algorithm and Chou's Pseudo Amino Acid Composition for Predicting Protein Subcellular Localization. Protein \& Peptide Letters, 18, 1219-1225. https://doi.org/10.2174/092986611797642797

29. Lin, J., Wang, Y. and Xu, X. (2011) A Novel Ensemble and Composite Approach for Classifying Proteins Based on Chou's Pseudo Amino Acid Composition. African Journal of Biotechnology, 10, 16963-16968. https://doi.org/10.5897/AJB11.429

30. Mohabatkar, H., Mohammad Beigi, M. and Esmaeili, A. (2011) Prediction of GABA(A) Receptor Proteins Using the Concept of Chou's Pseudo Amino Acid Composition and Support Vector Machine. Journal of Theoretical Biology, 281, 18-23. https://doi.org/10.1016/j.jtbi.2011.04.017

31. Mohammad, B.M., Behjati, M. and Mohabatkar, H. (2011) Prediction of Metalloproteinase Family Based on the Concept of Chou's Pseudo Amino Acid Composition Using a Machine Learning Approach. Journal of Structural and Functional Genomics, 12, 191-197. https://doi.org/10.1007/s10969-011-9120-4

32. Qiu, J.D., Suo, S.B., Sun, X.Y., Shi, S.P. and Liang, R.P. (2011) OligoPred: A Web-Server for Predicting Homo-Oligomeric Proteins by Incorporating Discrete Wavelet Transform into Chou's Pseudo Amino Acid Composition. Journal of Molecular Graphics \& Modelling, 30, 129-134. https://doi.org/10.1016/j.jmgm.2011.06.014

33. Zou, D., He, Z., He, J. and Xia, Y. (2011) Supersecondary Structure Prediction Using Chou's Pseudo Amino Acid Composition. Journal of Computational Chemistry, 32, 271-278. https://doi.org/10.1002/jcc.21616

34. Cao, J.Z., Liu, W.Q. and Gu, H. (2012) Predicting Viral Protein Subcellular Localization with Chou's Pseudo Amino Acid Composition and Imbalance-Weighted Multi-Label K-Nearest Neighbor Algorithm. Protein and Peptide Letters, 19, 1163-1169. https://doi.org/10.2174/092986612803216999

35. Chen, C., Shen, Z.B. and Zou, X.Y. (2012) Dual-Layer Wavelet SVM for Predicting Protein Structural Class via the General Form of Chou's Pseudo Amino Acid Composition. Protein \& Peptide Letters, 19, 422-429. https://doi.org/10.2174/092986612799789332

36. Du, P., Wang, X., Xu, C. and Gao, Y. (2012) PseAAC-Builder: A Cross-Platform Stand-Alone Program for Generating Various Special Chou's Pseudo Amino Acid Compositions. Analytical Biochemistry, 425, 117-119. https://doi.org/10.1016/j.ab.2012.03.015

37. Fan, G.L. and Li, Q.Z. (2012) Predict Mycobacterial Proteins Subcellular Locations by Incorporating Pseudo-Average Chemical Shift into the General Form of Chou's Pseudo Amino Acid Composition. Journal of Theoretical Biology, 304, 88-95. https://doi.org/10.1016/j.jtbi.2012.03.017

38. Fan, G.L. and Li, Q.Z. (2012) Predicting Protein Submitochondria Locations by Combining Different Descriptors into the General Form of Chou's Pseudo Amino Acid Composition. Amino Acids, 43, 545-555. https://doi.org/10.1007/s00726-011-1143-4

39. Li, L.Q., Zhang, Y., Zou, L.Y., Zhou, Y. and Zheng, X.Q. (2012) Prediction of Protein Subcellular Multi-Localization Based on the General form of Chou's Pseudo Amino Acid Composition. Protein \& Peptide Letters, 19, 375-387. https://doi.org/10.2174/092986612799789369

40. Liu, L., Hu, X.Z., Liu, X.X., Wang, Y. and Li, S.B. (2012) Predicting Protein Fold Types by the General Form of Chou's Pseudo Amino Acid Composition: Approached from Optimal Feature Extractions. Protein \& Peptide Letters, 19, 439-449. https://doi.org/10.2174/092986612799789378

41. Nanni, L., Brahnam, S. and Lumini, A. (2012) Wavelet Images and Chou's Pseudo Amino Acid Composition for Protein Classification. Amino Acids, 43, 657-665. https://doi.org/10.1007/s00726-011-1114-9

42. Nanni, L., Lumini, A., Gupta, D. and Garg, A. (2012) Identifying Bacterial Virulent Proteins by Fusing a Set of 
Classifiers Based on Variants of Chou's Pseudo Amino Acid Composition and on Evolutionary Information. IEEE-ACM Transaction on Computational Biolology and Bioinformatics, 9, 467-475.

https://doi.org/10.1109/TCBB.2011.117

43. Niu, X.H., Hu, X.H., Shi, F. and Xia, J.B. (2012) Predicting Protein Solubility by the General Form of Chou's Pseudo Amino Acid Composition: Approached from Chaos Game Representation and Fractal Dimension. Protein \& Peptide Letters, 19, 940-948. https://doi.org/10.2174/092986612802084492

44. Ren, L.Y., Zhang, Y.S. and Gutman, I. (2012) Predicting the Classification of Transcription Factors by Incorporating Their Binding Site Properties into a Novel Mode of Chou's Pseudo Amino Acid Composition. Protein \& Peptide Letters, 19, 1170-1176. https://doi.org/10.2174/092986612803217088

45. Zhao, X.W., Ma, Z.Q. and Yin, M.H. (2012) Predicting Protein-Protein Interactions by Combing Various Sequence-Derived Features into the General Form of Chou's Pseudo Amino Acid Composition. Protein \& Peptide Letters, 19, 492-500. https://doi.org/10.2174/092986612800191080

46. Zia-ur-Rehman and Khan, A. (2012) Identifying GPCRs and Their Types with Chou's Pseudo Amino Acid Composition: An Approach from Multi-Scale Energy Representation and Position Specific Scoring Matrix. Protein \& Peptide Letters, 19, 890-903. https://doi.org/10.2174/092986612801619589

47. Chen, Y.K. and Li, K.B. (2013) Predicting Membrane Protein Types by Incorporating Protein Topology, Domains, Signal Peptides, and Physicochemical Properties into the General Form of Chou's Pseudo Amino Acid Composition. Journal of Theoretical Biology, 318, 1-12. https://doi.org/10.1016/j.jtbi.2012.10.033

48. Fan, G.L. and Li, Q.Z. (2013) Discriminating Bioluminescent Proteins by Incorporating Average Chemical Shift and Evolutionary Information into the General Form of Chou's Pseudo Amino Acid Composition. Journal of Theoretical Biology, 334, 45-51. https://doi.org/10.1016/j.jtbi.2013.06.003

49. Georgiou, D.N., Karakasidis, T.E. and Megaritis, A.C. (2013) A Short Survey on Genetic Sequences, Chou's Pseudo Amino Acid Composition and Its Combination with Fuzzy Set Theory. The Open Bioinformatics Journal, 7, 41-48. https://doi.org/10.2174/1875036201307010041

50. Gupta, M.K., Niyogi, R. and Misra, M. (2013) An Alignment-Free Method to Find Similarity among Protein Sequences via the General Form of Chou's Pseudo Amino Acid Composition. SAR and QSAR in Environmental Research, 24, 597-609. https://doi.org/10.1080/1062936X.2013.773378

51. Huang, C. and Yuan, J. (2013) Using Radial Basis Function on the General Form of Chou's Pseudo Amino Acid Composition and PSSM to Predict Subcellular Locations of Proteins with Both Single and Multiple Sites. Biosystems, 113, 50-57. https://doi.org/10.1016/j.biosystems.2013.04.005

52. Huang, C. and Yuan, J.Q. (2013) A Multilabel Model Based on Chou's Pseudo Amino Acid Composition for Identifying Membrane Proteins with Both Single and Multiple Functional Types. The Journal of Membrane Biology, 246, 327-334. https://doi.org/10.1007/s00232-013-9536-9

53. Huang, C. and Yuan, J.Q. (2013) Predicting Protein Subchloroplast Locations with Both Single and Multiple Sites via Three Different Modes of Chou's Pseudo Amino Acid Compositions. Journal of Theoretical Biology, 335, 205-212. https://doi.org/10.1016/j.jtbi.2013.06.034

54. Khosravian, M., Faramarzi, F.K., Beigi, M.M., Behbahani, M. and Mohabatkar, H. (2013) Predicting Antibacterial Peptides by the Concept of Chou's Pseudo Amino Acid Composition and Machine Learning Methods. Protein \& Peptide Letters, 20, 180-186. https://doi.org/10.2174/092986613804725307

55. Lin, H., Ding, C., Yuan, L.-F., Chen, W., Ding, H., Li, Z.-Q., Guo, F.-B., Huang, J. and Rao, N.-N. (2013) Predicting Subchloroplast Locations of Proteins Based on the General Form of Chou's Pseudo Amino Acid Composition: Approached from Optimal Tripeptide Composition. International Journal of Biomethmatics, 6, Article ID: 1350003. https://doi.org/10.1142/S1793524513500034 
56. Liu, B., Wang, X., Zou, Q., Dong, Q. and Chen, Q. (2013) Protein Remote Homology Detection by Combining Chou's Pseudo Amino Acid Composition and Profile-Based Protein Representation. Molecular Informatics, 32, 775-782. https://doi.org/10.1002/minf.201300084

57. Mohabatkar, H., Beigi, M.M., Abdolahi, K. and Mohsenzadeh, S. (2013) Prediction of Allergenic Proteins by Means of the Concept of Chou's Pseudo Amino Acid Composition and a Machine Learning Approach. Medicinal Chemistry, 9, 133-137. https://doi.org/10.2174/157340613804488341

58. Qin, Y.F., Zheng, L. and Huang, J. (2013) Locating Apoptosis Proteins by Incorporating the Signal Peptide Cleavage Sites into the General Form of Chou's Pseudo Amino Acid Composition. International Journal of Quantum Chemistry, 113, 1660-1667. https://doi.org/10.1002/qua.24383

59. Sarangi, A.N., Lohani, M. and Aggarwal, R. (2013) Prediction of Essential Proteins in Prokaryotes by Incorporating Various Physico-Chemical Features into the General form of Chou's Pseudo Amino Acid Composition. Protein \& Peptide Letters, 20, 781-795. https://doi.org/10.2174/0929866511320070008

60. Wan, S., Mak, M.W. and Kung, S.Y. (2013) GOASVM: A Subcellular Location Predictor by Incorporating Term-Frequency Gene Ontology into the General Form of Chou's Pseudo Amino Acid Composition. Journal of Theoretical Biology, 323, 40-48. https://doi.org/10.1016/j.jtbi.2013.01.012

61. Wang, X., Li, G.Z. and Lu, W.C. (2013) Virus-ECC-mPLoc: A Multi-Label Predictor for Predicting the Subcellular Localization of Virus Proteins with Both Single and Multiple Sites Based on a General Form of Chou's Pseudo Amino Acid Composition. Protein \& Peptide Letters, 20, 309-317. https://doi.org/10.2174/092986613804910608

62. Niu, X.H., et al. (2013) Using the Concept of Chou's Pseudo Amino Acid Composition to Predict Protein Solubility: An Approach with Entropies in Information Theory. Journal of Theoretical Biology, 332, 211-217. https://doi.org/10.1016/j.jtbi.2013.03.010

63. Du, P., Gu, S. and Jiao, Y. (2014) PseAAC-General: Fast Building Various Modes of General Form of Chou's Pseudo Amino Acid Composition for Large-Scale Protein Datasets. International Journal of Molecular Sciences, 15, 3495-3506. https://doi.org/10.3390/ijms15033495

64. Hajisharifi, Z., Piryaiee, M., Mohammad Beigi, M., Behbahani, M. and Mohabatkar, H. (2014) Predicting Anticancer Peptides with Chou's Pseudo Amino Acid Composition and Investigating Their Mutagenicity via Ames Test. Journal of Theoretical Biology, 341, 34-40. https://doi.org/10.1016/j.jtbi.2013.08.037

65. Jia, C., Lin, X. and Wang, Z. (2014) Prediction of Protein S-Nitrosylation Sites Based on Adapted Normal Distribution Bi-Profile Bayes and Chou's Pseudo Amino Acid Composition. International Journal of Molecular Sciences, 15, 10410-10423. https://doi.org/10.3390/ijms150610410

66. Kong, L., Zhang, L. and Lv, J. (2014) Accurate Prediction of Protein Structural Classes by Incorporating Predicted Secondary Structure Information into the General Form of Chou's Pseudo Amino Acid Composition. Journal of Theoretical Biology, 344, 12-18. https://doi.org/10.1016/j.jtbi.2013.11.021

67. Nanni, L., Brahnam, S. and Lumini, A. (2014) Prediction of Protein Structure Classes by Incorporating Different Protein Descriptors into General Chou's Pseudo Amino Acid Composition. Journal of Theoretical Biology, 360, 109-116. https://doi.org/10.1016/j.jtbi.2014.07.003

68. Zhang, J., Sun, P., Zhao, X. and Ma, Z. (2014) PECM: Prediction of Extracellular Matrix Proteins Using the Concept of Chou's Pseudo Amino Acid Composition. Journal of Theoretical Biology, 363, 412-418. https://doi.org/10.1016/j.jtbi.2014.08.002

69. Zhang, L., Zhao, X. and Kong, L. (2014) Predict Protein Structural Class for Low-Similarity Sequences by Evolutionary Difference Information into the General Form of Chou's Pseudo Amino Acid Composition. Journal of Theoretical Biology, 355, 105-110. https://doi.org/10.1016/j.jtbi.2014.04.008 
70. Zuo, Y.C., Peng, Y., Liu, L., Chen, W., Yang, L. and Fan, G.L. (2014) Predicting Peroxidase Subcellular Location by Hybridizing Different Descriptors of Chou's Pseudo Amino Acid Patterns. Analytical Biochemistry, 458, 14-19. https://doi.org/10.1016/j.ab.2014.04.032

71. Ali, F. and Hayat, M. (2015) Classification of Membrane Protein Types Using Voting Feature Interval in Combination with Chou's Pseudo Amino Acid Composition. Journal of Theoretical Biology, 384, 78-83. https://doi.org/10.1016/j.jtbi.2015.07.034

72. Fan, G.L., Zhang, X.Y., Liu, Y.L., Nang, Y. and Wang, H. (2015) DSPMP: Discriminating Secretory Proteins of Malaria Parasite by Hybridizing Different Descriptors of Chou's Pseudo Amino Acid Patterns. Journal of Computational Chemistry, 36, 2317-2327. https://doi.org/10.1002/jcc.24210

73. Huang, C. and Yuan, J.Q. (2015) Simultaneously Identify Three Different Attributes of Proteins by Fusing Their Three Different Modes of Chou's Pseudo Amino Acid Compositions. Protein \& Peptide Letters, 22, 547-556. https://doi.org/10.2174/0929866522666150209151344

74. Khan, Z.U., Hayat, M. and Khan, M.A. (2015) Discrimination of Acidic and Alkaline Enzyme Using Chou's Pseudo Amino Acid Composition in Conjunction with Probabilistic Neural Network Model. Journal of Theoretical Biology, 365, 197-203. https://doi.org/10.1016/j.jtbi.2014.10.014

75. Kumar, R., Srivastava, A., Kumari, B. and Kumar, M. (2015) Prediction of Beta-Lactamase and Its Class by Chou's Pseudo Amino Acid Composition and Support Vector Machine. Journal of Theoretical Biology, 365, 96-103. https://doi.org/10.1016/j.jtbi.2014.10.008

76. Wang, X., Zhang, W., Zhang, Q. and Li, G.Z. (2015) MultiP-SChlo: Multi-Label Protein Subchloroplast Localization Prediction with Chou's Pseudo Amino Acid Composition and a Novel Multi-Label Classifier. Bioinformatics, 31, 2639-2645. https://doi.org/10.1093/bioinformatics/btv212

77. Jiao, Y.S. and Du, P.F. (2016) Prediction of Golgi-Resident Protein Types Using General Form of Chou's Pseudo Amino Acid Compositions: Approaches with Minimal Redundancy Maximal Relevance Feature Selection. Journal of Theoretical Biology, 402, 38-44. https://doi.org/10.1016/j.jtbi.2016.04.032

78. Tang, H., Chen, W. and Lin, H. (2016) Identification of Immunoglobulins Using Chou's Pseudo Amino Acid Composition with Feature Selection Technique. Molecular BioSystems, 12, 1269-1275. https://doi.org/10.1039/C5MB00883B

79. Zou, H.L. and Xiao, X. (2016) Predicting the Functional Types of Singleplex and Multiplex Eukaryotic Membrane Proteins via Different Models of Chou's Pseudo Amino Acid Compositions. The Journal of Membrane Biolog, 249, 23-29. https://doi.org/10.1007/s00232-015-9830-9

80. Huo, H., Li, T., Wang, S., Lv, Y., Zuo, Y. and Yang, L. (2017) Prediction of Presynaptic and Postsynaptic Neurotoxins by Combining Various Chou's Pseudo Components. Scientific Reports, 7, Article No. 5827. https://doi.org/10.1038/s41598-017-06195-y

81. Rahimi, M., Bakhtiarizadeh, M.R. and Mohammadi-Sangcheshmeh, A. (2017) OOgenesis_Pred: A Sequence-Based Method for Predicting Oogenesis Proteins by Six Different Modes of Chou's Pseudo Amino Acid Composition. Journal of Theoretical Biology, 414, 128-136. https://doi.org/10.1016/j.jtbi.2016.11.028

82. Tripathi, P. and Pandey, P.N. (2017) A Novel Alignment-Free Method to Classify Protein Folding Types by Combining Spectral Graph Clustering with Chou's Pseudo Amino Acid Composition. Journal of Theoretical Biology, 424, 49-54. https://doi.org/10.1016/j.jtbi.2017.04.027

83. Yu, B., Lou, L., Li, S., Zhang, Y., Qiu, W., Wu, X., Wang, M. and Tian, B. (2017) Prediction of Protein Structural Class for Low-Similarity Sequences Using Chou's Pseudo Amino Acid Composition and Wavelet Denoising. Journal of Molecular Graphics and Modelling, 76, 260-273. https://doi.org/10.1016/j.jmgm.2017.07.012

84. Al Maruf, M.A. and Shatabda, S. (2018) iRSpot-SF: Prediction of Recombination Hotspots by Incorporating 
Sequence Based Features into Chou's Pseudo Components. Genomics, 111, 966-972.

https://doi.org/10.1016/j.ygeno.2018.06.003

85. Arif, M., Hayat, M. and Jan, Z. (2018) iMem-2LSAAC: A Two-Level Model for Discrimination of Membrane Proteins and Their Types by Extending the Notion of SAAC into Chou's Pseudo Amino Acid Composition. Journal of Theoretical Biology, 442, 11-21. https://doi.org/10.1016/j.jtbi.2018.01.008

86. Cui, X., Yu, Z., Yu, B., Wang, M., Tian, B. and Ma, Q. (2018) UbiSitePred: A Novel Method for Improving the Accuracy of Ubiquitination Sites Prediction by Using LASSO to Select the Optimal Chou's Pseudo Components. Chemometrics and Intelligent Laboratory Systems, 184, 28-43. https://doi.org/10.1016/j.chemolab.2018.11.012

87. Mei, J. and Zhao, J. (2018) Prediction of HIV-1 and HIV-2 Proteins by Using Chou's Pseudo Amino Acid Compositions and Different Classifiers. Scientific Reports, 8, Article No. 2359.

https://doi.org/10.1038/s41598-018-20819-x

88. Qiu, W., Li, S., Cui, X., Yu, Z., Wang, M., Du, J., Peng, Y. and Yu, B. (2018) Predicting Protein Submitochondrial Locations by Incorporating the Pseudo-Position Specific Scoring Matrix into the General Chou's Pseudo-Amino Acid Composition. Journal of Theoretical Biology, 450, 86-103.

https://doi.org/10.1016/j.jtbi.2018.04.026

89. Zhang, L. and Kong, L. (2018) iRSpot-ADPM: Identify Recombination Spots by Incorporating the Associated Dinucleotide Product Model into Chou's Pseudo Components. Journal of Theoretical Biology, 441, 1-8. https://doi.org/10.1016/j.jtbi.2017.12.025

90. Zhang, S., Yang, K., Lei, Y. and Song, K. (2018) iRSpot-DTS: Predict Recombination Spots by Incorporating the Dinucleotide-Based Spare-Cross Covariance Information into Chou's Pseudo Components. Genomics, 11, 457-464.

91. Zhao, W., Wang, L., Zhang, T.X., Zhao, Z.N. and Du, P.F. (2018) A Brief Review on Software Tools in Generating Chou's Pseudo-Factor Representations for All Types of Biological Sequences. Protein \& Peptide Letters, 25, 822-829. https://doi.org/10.2174/0929866525666180905111124

92. Al Maruf, M.A. and Shatabda, S. (2019) iRSpot-SF: Prediction of Recombination Hotspots by Incorporating Sequence Based Features into Chou's Pseudo Components. Genomics, 111, 966-972.

https://doi.org/10.1016/j.ygeno.2018.06.003

93. Nosrati, M., Mohabatkar, H. and Behbahani, M. (2019) Introducing of an Integrated Artificial Neural Network and Chou's Pseudo Amino Acid Composition Approach for Computational Epitope-Mapping of Crimean-Congo Haemorrhagic Fever Virus Antigens. International Immunopharmacology, 78, Article ID: 106020. https://www.sciencedirect.com/science/article/pii/S1567576919321277

https://doi.org/10.1016/j.intimp.2019.106020

94. Pan, Y., Wang, S., Zhang, Q., Lu, Q., Su, D., Zuo, Y. and Yang, L. (2019) Analysis and Prediction of Animal Toxins by Various Chou's Pseudo Components and Reduced Amino Acid Compositions. Journal of Theoretical Biology, 462, 221-229. https://doi.org/10.1016/j.jtbi.2018.11.010

95. Tahir, M., Tayara, H. and Chong, K.T. (2019) iRNA-PseKNC(2methyl): Identify RNA 2'-O-Methylation Sites by Convolution Neural Network and Chou's Pseudo Components. Journal of Theoretical Biology, 465, 1-6. https://doi.org/10.1016/j.jtbi.2018.12.034

96. Tian, B., Wu, X., Chen, C., Qiu, W., Ma, Q. and Yu, B. (2019) Predicting Protein-Protein Interactions by Fusing Various Chou's Pseudo Components and Using Wavelet Denoising Approach. Journal of Theoretical Biology, 462, 329-346. https://doi.org/10.1016/j.jtbi.2018.11.011

97. Zhang, L. and Kong, L. (2019) iRSpot-PDI: Identification of Recombination Spots by Incorporating Dinucleotide Property Diversity Information into Chou's Pseudo Components. Genomics, 111, 457-464. https://doi.org/10.1016/j.ygeno.2018.03.003 
98. Zhang, S., Yang, K., Lei, Y. and Song, K. (2019) iRSpot-DTS: Predict Recombination Spots by Incorporating the Dinucleotide-Based Spare-Cross Covariance Information into Chou's Pseudo Components. Genomics, 111, 1760-1770. https://doi.org/10.1016/j.ygeno.2018.11.031

99. Nosrati, M., Mohabatkar, H. and Behbahani, M. (2020) Introducing of an Integrated Artificial Neural Network and Chou's Pseudo Amino Acid Composition Approach for Computational Epitope-Mapping of Crimean-Congo Haemorrhagic Fever Virus Antigens. International Immunopharmacology, 78, Article ID: 106020. https://doi.org/10.1016/j.intimp.2019.106020

100. Butt, A.H. and Khan, Y.D. (2018) Prediction of S-Sulfenylation Sites Using Statistical Moments Based Features via Chou's 5-Step Rule. International Journal of Peptide Research and Therapeutics. https://doi.org/10.1007/s10989-019-09931-2

101. Awais, M., Hussain, W., Khan, Y.D., Rasool, N., Khan, S.A. and Chou, K.C. (2019) iPhosH-PseAAC: Identify Phosphohistidine Sites in Proteins by Blending Statistical Moments and Position Relative Features According to the Chou's 5-Step Rule and General Pseudo Amino Acid Composition. IEEE/ ACM Transactions on Computational Biology and Bioinformatics. https://doi.org/10.1109/TCBB.2019.2919025

102. Barukab, O., Khan, Y.D., Khan, S.A. and Chou, K.C. (2019) iSulfoTyr-PseAAC: Identify Tyrosine Sulfation Sites by Incorporating Statistical Moments via Chou's 5-Steps Rule and Pseudo Components. Current Genomics, 20, 306-320. https://doi.org/10.2174/1389202920666190819091609

103. Butt, A.H. and Khan, Y.D. (2019) Prediction of S-Sulfenylation Sites Using Statistical Moments Based Features via Chou's 5-Step Rule. International Journal of Peptide Research and Therapeutics (IJPRT). https://doi.org/10.1007/s10989-019-09931-2

104. Chen, Y. and Fan, X. (2019) Use Chou's 5-Steps Rule to Reveal Active Compound and Mechanism of Shuangsheng Pingfei San on Idiopathic Pulmonary Fibrosis. Current Molecular Medicine. https://doi.org/10.2174/1566524019666191011160543

105. Du, X., Diao, Y., Liu, H. and Li, S. (2019) MsDBP: Exploring DNA-Binding Proteins by Integrating Multi-Scale Sequence Information via Chou's 5-Steps Rule. Journal of Proteome Research, 18, 3119-3132. https://doi.org/10.1021/acs.jproteome.9b00226

106. Dutta, A., Dalmia, A., Singh, K.K. and Anand, A. (2019) Using the Chou's 5-Steps Rule to Predict Splice Junctions with Interpretable Bidirectional Long Short-Term Memory Networks. Computers in Biology and Medicine, 116, Article ID: 103558. https://doi.org/10.1016/j.compbiomed.2019.103558

107. Ehsan, A., Mahmood, M.K., Khan, Y.D., Barukab, O.M., Khan, S.A. and Chou, K.C. (2019) iHyd-PseAAC (EPSV): Identify Hydroxylation Sites in Proteins by Extracting Enhanced Position and Sequence Variant Feature via Chou's 5-Step Rule and General Pseudo Amino Acid Composition. Current Genomics, 20, 124-133. https://doi.org/10.2174/1389202920666190325162307

108. Hussain, W., Khan, S.D., Rasool, N., Khan, S.A. and Chou, K.C. (2019) SPalmitoylC-PseAAC: A Sequence-Based Model Developed via Chou's 5-Steps Rule and General PseAAC for Identifying S-Palmitoylation Sites in Proteins. Analytical Biochemistry, 568, 14-23. https://doi.org/10.1016/j.ab.2018.12.019

109. Hussain, W., Khan, Y.D., Rasool, N., Khan, S.A. and Chou, K.C. (2019) SPrenylC-PseAAC: A Sequence-Based Model Developed via Chou's 5-Steps Rule and General PseAAC for Identifying S-Prenylation Sites in Proteins. Journal of Theoretical Biology, 468, 1-11. https://doi.org/10.1016/j.jtbi.2019.02.007

110. Jun, Z. and Wang, S.Y. (2019) Identify Lysine Neddylation Sites Using Bi-Profile Bayes Feature Extraction via the Chou's 5-Steps Rule and General Pseudo Components. Current Genomics, 20, 592-601. https://doi.org/10.2174/1389202921666191223154629

111. Khan, S., Khan, M., Iqbal, N., Hussain, T., Khan, S.A. and Chou, K.C. (2019) A Two-Level Computation Model Based on Deep Learning Algorithm for Identification of piRNA and Their Functions via Chou's 5-Steps Rule. 
Human Genetics. https://doi.org/10.1007/s10989-019-09887-3

112. Khan, Z.U., Ali, F., Khan, I.A., Hussain, Y. and Pi, D. (2019) iRSpot-SPI: Deep Learning-Based Recombination Spots Prediction by Incorporating Secondary Sequence Information Coupled with Physio-Chemical Properties via Chou's 5-Step Rule and Pseudo Components. Chemometrics and Intelligent Laboratory Systems (CHEMOLAB), 189, 169-180. https://doi.org/10.1016/j.chemolab.2019.05.003

113. Lan, J., Liu, J., Liao, C., Merkler, D.J., Han, Q. and Li, J. (2019) A Study for Therapeutic Treatment against Parkinson's Disease via Chou's 5-Steps Rule. Current Topics in Medicinal Chemistry, 19, 2318-2333.

http://www.eurekaselect.com/175887/article https://doi.org/10.2174/1568026619666191019111528

114. Le, N.Q.K. (2019) iN6-methylat (5-Step): Identifying DNA N(6)-Methyladenine Sites in Rice Genome Using Continuous Bag of Nucleobases via Chou's 5-Step Rule. Molecular Genetics and Genomics. MGG, 294, 1173-1182. https://doi.org/10.1007/s00438-019-01570-y

115. Le, N.Q.K., Yapp, E.K.Y., Ho, Q.T., Nagasundaram, N., Ou, Y.Y. and Yeh, H.Y. (2019) iEnhancer-5Step: Identifying Enhancers Using Hidden Information of DNA Sequences via Chou's 5-Step Rule and Word Embedding. Analytical Biochemistry, 571, 53-61. https://doi.org/10.1016/j.ab.2019.02.017

116. Le, N.Q.K., Yapp, E.K.Y., Ou, Y.Y. and Yeh, H.Y. (2019) iMotor-CNN: Identifying Molecular Functions of Cytoskeleton Motor Proteins Using 2D Convolutional Neural Network via Chou's 5-Step Rule. Analytical Biochemistry, 575, 17-26. https://doi.org/10.1016/j.ab.2019.03.017

117. Liang, R., Xie, J., Zhang, C., Zhang, M., Huang, H., Huo, H., Cao, X. and Niu, B. (2019) Identifying Cancer Targets Based on Machine Learning Methods via Chou's 5-Steps Rule and General Pseudo Components. Current Topics in Medicnal Chemistry, 19, 2301-2317. https://doi.org/10.2174/1568026619666191016155543

118. Liang, Y. and Zhang, S. (2019) Identifying DNase I Hypersensitive Sites Using Multi-Features Fusion and F-Score Features Selection via Chou's 5-Steps Rule. Biophysical Chemistry, 253, Article ID: 106227. https://doi.org/10.1016/j.bpc.2019.106227

119. Liu, Z., Dong, W., Jiang, W. and He, Z. (2019) csDMA: An Improved Bioinformatics Tool for Identifying DNA 6 mA Modifications via Chou's 5-Step Rule. Scientific Reports, 9, Article No. 13109. https://doi.org/10.1038/s41598-019-49430-4

120. Malebary, S.J., Rehman, M.S.U. and Khan, Y.D. (2019) iCrotoK-PseAAC: Identify Lysine Crotonylation Sites by Blending Position Relative Statistical Features According to the Chou's 5-Step Rule. PLoS ONE, 14, e0223993. https://doi.org/10.1371/journal.pone.0223993

121. Nazari, I., Tahir, M., Tayari, H. and Chong, K.T. (2019) iN6-Methyl (5-Step): Identifying RNA N6-Methyladenosine Sites Using Deep Learning Mode via Chou's 5-Step Rules and Chou's General PseKNC. Chemometrics and Intelligent Laboratory Systems (CHEMOLAB), 193, Article ID: 103811. https://doi.org/10.1016/j.chemolab.2019.103811

122. Ning, Q., Ma, Z. and Zhao, X. (2019) dForml(KNN)-PseAAC: Detecting Formylation Sites from Protein Sequences Using K-Nearest Neighbor Algorithm via Chou's 5-Step Rule and Pseudo Components. Journal of Theoretical Biology, 470, 43-49. https://doi.org/10.1016/j.jtbi.2019.03.011

123. Tahir, M., Tayara, H. and Chong, K.T. (2019) iDNA6mA (5-Step Rule): Identification of DNA N6-Methyladenine Sites in the Rice Genome by Intelligent Computational Model via Chou's 5-Step Rule. CHEMOLAB, 189, 96-101. https://doi.org/10.1016/j.chemolab.2019.04.007

124. Wiktorowicz, A., Wit, A., Dziewierz, A., Rzeszutko, L., Dudek, D. and Kleczynski, P. (2019) Calcium Pattern Assessment in Patients with Severe Aortic Stenosis via the Chou's 5-Steps Rule. Current Pharmaceutical Design, 25, 3769-3775. https://doi.org/10.2174/1381612825666190930101258 
125. Yang, L., Lv, Y., Wang, S., Zhang, Q., Pan, Y., Su, D., Lu, Q. and Zuo, Y. (2019) Identifying FL11 Subtype by Characterizing Tumor Immune Microenvironment in Prostate Adenocarcinoma via Chou's 5-Steps Rule. Genomics, 112, 1500-1515. https://doi.org/10.1016/j.ygeno.2019.08.021

126. Akbar, S., Rahman, A.U., Hayat, M., et al. (2020) cACP: Classifying Anticancer Peptides Using Discriminative Intelligent Model via Chou's 5-Step Rules and General Pseudo Components. Chemometrics and Intelligent Laboratory (CHEMOLAB), 196, Article ID: 103912. https://doi.org/10.1016/j.chemolab.2019.103912

127. Akmal, M.A., Hussain, W., Rasool, N., Khan, Y.D., Khan, S.A. and Chou, K.C. (2020) Using Chou's 5-Steps Rule to Predict O-Linked Serine Glycosylation Sites by Blending Position Relative Features and Statistical Moment. IEEE/ ACM Transactions on Computational Biology and Bioinformatics. (In Press) https://doi.org/10.1109/TCBB.2020.2968441

128. Charoenkwan, P., Schaduangrat, N., Nantasenamat, C., Piacham, T. and Shoombuatong, W. (2020) iQSP: A Sequence-Based Tool for the Prediction and Analysis of Quorum Sensing Peptides via Chou's 5-Steps Rule and Informative Physicochemical Properties. International Journal of Molecular Sciences, 21, 75. https://doi.org/10.3390/ijms21010075

129. Charoenkwan, P., Schaduangrat, N., Nantasenamat, C., Piacham, T. and Shoombuatong, W. (2020) iQSP: A Sequence-Based Tool for the Prediction and Analysis of Quorum Sensing Peptides via Chou's 5-Steps Rule and Informative Physicochemical Properties. International Journal of Molecular Sciences, 21, 75. https://doi.org/10.3390/ijms21010075

130. Chen, Y. and Fan, X. (2020) Use of Chou's 5-Steps Rule to Reveal Active Compound and Mechanism of Shuangshen Pingfei San on Idiopathic Pulmonary Fibrosis. Current Molecular Medicine, 20, 220-230. https://doi.org/10.2174/1566524019666191011160543

131. Dobosz, R., Mucko, J. and Gawinecki, R. (2020) Using Chou's 5-Step Rule to Evaluate the Stability of Tautomers: Susceptibility of 2-[(Phenylimino)-methyl]-cyclohexane-1,3-diones to Tautomerization Based on the Calculated Gibbs Free Energies. Energies, 13, 183. https://doi.org/10.3390/en13010183

132. Du, L., Meng, Q., Jiang, H. and Li, Y. (2020) Using Evolutionary Information and Multi-Label Linear Discriminant Analysis to Predict the Subcellular Location of Multi-Site Bacterial Proteins via Chou's 5-Steps Rule. IEEE Access, 8, 56452-56461. https://doi.org/10.1109/ACCESS.2020.2982160

133. Dutta, A., Dalmia, A., Singh, K.K. and Anand, A. (2020) Using the Chou's 5-Steps Rule to Predict Splice Junctions with Interpretable Bidirectional Long Short-Term Memory Networks. Computers in Biology and Medicine, 116, Article ID: 103558. https://doi.org/10.1016/j.compbiomed.2019.103558

134. Ju, Z. and Wang, S.Y. (2020) Prediction of Lysine Formylation Sites Using the Composition of k-Spaced Amino Acid Pairs via Chou's 5-Steps Rule and General Pseudo Components. Genomics, 112, 859-866. https://doi.org/10.1016/j.ygeno.2019.05.027

135. Kabir, M., Ahmad, S., Iqbal, M. and Hayat, M. (2020) iNR-2L: A Two-Level Sequence-Based Predictor Developed via Chou's 5-Steps Rule and General PseAAC for Identifying Nuclear Receptors and Their Families. Genomics, 112, 276-285. https://doi.org/10.1016/j.ygeno.2019.02.006

136. Khan, Y.D., Amin, N., Hussain, W., Rasool, N., Khan, S.A. and Chou, K.C. (2020) iProtease-PseAAC(2L): A Two-Layer Predictor for Identifying Proteases and Their Types Using Chou's 5-Step-Rule and General PseAAC. Analytical Biochemistry, 588, Article ID: 113477. https://doi.org/10.1016/j.ab.2019.113477

137. Lin, W., Xiao, X., Qiu, W. and Chou, K.C. (2020) Use Chou's 5-Steps Rule to Predict Remote Homology Proteins by Merging Grey Incidence Analysis and Domain Similarity Analysis. Natural Science, 12, 181-198. https://doi.org/10.4236/ns.2020.123016

138. Vishnoi, S., Garg, P. and Arora, P. (2020) Physicochemical n-Grams Tool: A Tool for Protein Physicochemical Descriptor Generation via Chou's 5-Step Rule. Chemical Biology \& Drug Design, 95, 79-86. 
https://doi.org/10.1111/cbdd.13617

139. Vundavilli, H., Datta, A., Sima, C., Hua, J., Lopes, R. and Bittner, M. (2020) Using Chou's 5-Steps Rule to Model Feedback in Lung Cancer. IEEE Journal of Biomedical and Health Informatics, 21, 1-24. https://doi.org/10.1109/JBHI.2019.2958042

140. Yang, L., Lv, Y., Wang, S., Zhang, Q., Pan, Y., Su, D., Lu, Q. and Zuo, Y. (2020) Identifying FL11 Subtype by Characterizing Tumor Immune Microenvironment in Prostate Adenocarcinoma via Chou's 5-Steps Rule. Genomics, 112, 1500-1515. https://doi.org/10.1016/j.ygeno.2019.08.021 